
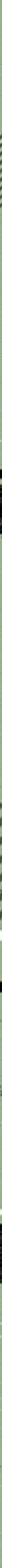


\title{
Avaliação do Programa Nacional de Produção e Uso de Biodiesel no Contexto do Desenvolvimento Regional e Inclusão Social
}

\author{
Evaluation of the National Program for the \\ Production and Use of Biodiesel in the context \\ of Regional Development and Social Inclusion
}

\author{
Pedro Gilberto Cavalcante Filho* | Antônio Márcio Buainain** \\ Marcelo Pereira da Cunha***
}

\begin{abstract}
Resumo
Este trabalho tem o objetivo de avaliar a experiência do Programa Nacional de Produção e Uso do Biodiesel (PNPB) no contexto do desenvolvimento regional nos últimos dez anos. A metodologia utilizada neste trabalho tem natureza descritiva, exploratória e explicativa mediante o levantamento bibliográfico, documental e análise do banco de dados da Agência Nacional do Petróleo, Gás Natural e Biocombustíveis (ANP) e do Selo Combustível Social (SCS). Os resultados indicam que as usinas se estabeleceram nas regiões tradicionalmente produtoras de soja, como Sul e Centro-Oeste, mostrando uma coordenação das forças de mercado e não da ação norteadora do Estado brasileiro e distorceu os objetivos de promoção do desenvolvimento regional no Norte e Nordeste. Essa condição se refletiu na concentração da inclusão social dos agricultores familiares sulistas, especificamente o Rio Grande do Sul, que apresenta um modelo de desenvolvimento agrícola e configurações sociais distintas das demais regiões, possibilitando maior nível de inclusão.
\end{abstract}

Palavras-chave: PNPB. Selo Combustível Social. Desenvolvimento Regional. Biodiesel. Agricultura familiar.

\begin{abstract}
This paper aims to evaluate the experience of the $\mathrm{Na}$ tional Biodiesel Production and Use Program (PNPB) in the context of regional development in the last ten years. The methodology used in this work has a descriptive, exploratory and explanatory nature through the bibliographic, documentary and analysis of the database of the National Agency of Petroleum, Natural Gas and Biofuels (ANP) and the Social Fuel Seal (SCS). The results indicate that the mills have established themselves in traditionally soy producing regions, such as the South and Midwest, showing a coordination of market forces and not the guiding action of the Brazilian State and distorted the objectives of promoting regional development in the North and Northeast. This condition was reflected in the concentration of social inclusion of southern family farmers, specifically Rio Grande do Sul, which presents a model of agricultural development and social configurations distinct from other regions, allowing a higher level of inclusion.
\end{abstract}

Keywords: PNPB. Social Fuel Seal. Regional development. Biodiesel. Family farming.

\footnotetext{
* Pedro Gilberto Cavalcante Filho

Economista, UFAC, MSc. (Desenvolvimento Econômico, Instituto de Economia/Unicamp), doutorando em Desenvolvimento Econômico pelo Instituto de Economia da Universidade Estadual de Campinas (IE/UNICAMP) na área de concentração de Economia Agrícola e Meio Ambiente. https://orcid.org/0000-0003-1776-0295. E-mail: pedro.gilberto@hotmail.com

** Antônio Márcio Buainain

Bacharel em Direito (UERj) e Economia (UCAM-RJ), Doutor em Economia (Instituto de Economia/Unicamp). Professor do Instituto de Economia da Unicamp, pesquisador do Núcleo de Economia Aplicada, Agricola e do Meio Ambiente (NEA+)/IE/Unicamp e do Instituto Nacional de Ciência e Tecnologia em Políticas Públicas, Estratégias e Desenvolvimento (INCT/PPED). https://orcid.org/0000-0002-1779-5589.E-mail: buainain@gmail.com

*** Marcelo Pereira da Cunha

Engenheiro Mecânico (Poli/USP), MSc. em Matemática Aplicada (Instituto de Matemática, Estatística e Computação Científica/Unicamp, Doutor em Planejamento de Sistemas Energéticos (Unicamp). Professor do Instituto de Economia da Unicamp e pesquisador do NEA+. https://orcid.org/0000-0002-1027-1694.

E-mail:mpcunha@unicamp.br
}

Recebido em 17 de abril de 2020. Aceito em 30 de junho de 2020. - http://dx.doi.org/10.51861/ded.dmv.2.001 


\section{INTRODUÇÃO}

O Programa Nacional de Produção e Uso do Biodiesel (PNPB) foi lançado em 2004 com objetivos ambiciosos. De um lado, incluir o biodiesel na matriz energética brasileira por meio da adição ao diesel convencional. De outro, com forte apelo e motivação para a promoção do desenvolvimento regional e a inclusão social da agricultura familiar, sendo uma opção econômica para as regióes pobres, condicionando ao uso de áreas ociosas e promovendo a recuperação de áreas degradadas (MDIC, 2006).

A estruturação do PNPB envolveu um arranjo institucional complexo, reunindo representantes de diversas áreas da cadeia produtiva do biodiesel e a criação de um Grupo de Trabalho Interministerial (GTI), que contou com a participação de diversos ministérios e agências reguladoras, e que tinha amplos poderes para definir desde as diretrizes até indicar os responsáveis pela coordenação e gestão em cada setor específico, da operacionalização de produção até a comercialização e o consumo (PEDROTI, 2013).

Para estimular a produção de biodiesel e alcançar as metas estabelecidas, o PNPB mobilizou um conjunto de instrumentos financeiros, tributários e regulatórios, sendo o mais importante a própria obrigatoriedade de mistura ao óleo diesel. As medidas adotadas incluíram incentivos fiscais, aprimoramento legislativo, financiamento em setores estratégicos da cadeia produtiva e a implementação do Selo Combustível Social (SCS). No tocante aos incentivos fiscais, o Governo Federal utilizou principalmente os critérios de incidência de contribuição do PIS/Pasep e da Cofins sobre a comercialização do biodiesel para impulsionar o desenvolvimento do setor, estabelecendo coeficientes de alíquotas reduzidas e diferenciados segundo o tipo de matéria-prima utilizado no processo produtivo, o fornecedor da matéria-prima (se oriunda ou não de produção da agricultura familiar) e a região onde a matéria-prima é produzida (BRASIL, 2005).

Com a regulamentação e o estabelecimento das condições de produção, comercialização e uso do biodiesel no âmbito do PNPB, a estrutura da cadeia produtiva do biodiesel se afirmou a partir da produção de soja, mas sem abandonar a promessa de fomentar a diversificação agrícola e de descentralização do abastecimento por meio de usinas de beneficiamento, implementadas em pontos estratégicos do território nacional por meio de incentivos fiscais, produtivos e creditícios proporcionados pelo Programa. A garantia de comercialização da produção foi estabelecida pela constituição do mercado institucional de biodiesel regulado pelos leilóes da Agência Nacional de Petróleo, Gás Natural e Biocombustíveis (ANP) (RODRIGUES, 2006).

Todo o arranjo institucional adotado pelo PNPB trouxe inovaçóes no modelo de gestão e coordenação da política energética brasileira, com desta- 
que para a introdução do objetivo de promover o desenvolvimento regional nas regiões Norte e Nordeste e, especialmente, pela inserção do caráter social no âmbito do Programa através da instituição do Selo Combustível Social, com o objetivo de promover a inclusão social da agricultura familiar na cadeia produtiva do biodiesel para esse segmento produtivo prover as usinas com o abastecimento de parte das matérias-primas (FARIA et al., 2013).

Abramovay e Magalhães (2007) afirmam que a criação do Selo Combustível Social representou uma significativa modificação no fundamento de ação do Estado. A aproximação entre empresas e organizações sindicais teve como regulador inicial o MDA, que atuou em dois eixos: a formalização de contratos entre empresas e sindicatos de agricultores,em conformidade comas normas do Selo; e fomento à criação de conselhos para o planejamento da produção de forma que os dois lados fossem representados. Com essa medida o MDA ampliou o escopo de sua atuação, estabelecendo vínculos com grandes empresas privadas do setor energético a fim de promover a inserção, e incluindo em sua agenda política temas como a gestão de cadeias de suprimento, funcionamento dosmercados, viabilidade econômica e política das medidas que estava sob sua responsabilidade.

O presente trabalho tem por objetivo avaliar a experiência do PNPB, tendo como base a constituição e a evolução da cadeia produtiva do biodiesel no Brasil à luz dos objetivos de desenvolvimento regional e da inclusão da agricultura familiar. Especificamente, busca-se identificar as principais regiốes produtoras de biodiesel com matéria-prima fornecida pela agricultura familiar adquiridas no âmbito do Selo Combustível Social.

Este estudo tem caráter exploratório e descritivo (GIL, 2008). A avaliação do PNPB dá-se com base na evolução do programa nas diferentes regióes do país, considerando os o volume de produção de biodiesel entre os 2009 e 2018. Os recursos metodológicos utilizados foram a pesquisa bibliográfica, documental e análise de banco de dados. Os dados utilizados para realizar a presente avaliação foram obtidos a partir dos Dados Estatísticos da ANP, para identificar a quantidade produzida de biodiesel e capacidade instalada, e da Secretaria de Agricultura Familiar e Cooperativismo (SAF), vinculada ao Ministério da Agricultura, pecuária e Abastecimento (MAPA), com o objetivo de consultar os dados do SCS.

\section{A EVOLUÇÃO DA CADEIA PRODUTIVA DO BIODIESEL NO BRASIL}

Seguindo o marco teórico apontado por Aydalot (1985) e Lima (2006), a Economia Regional investiga as razôes da distribuição das atividades econô- 
micas de forma heterogênea no âmbito de uma determinada região geográfica, a explicação de algumas localidades com economias antes desenvolvidas entrarem em crise e em processo de decadência e a proposta de normas de conduta para a execução de determinados objetivos econômicos e sociais de desenvolvimento regional que foram estabelecidos por políticas. Além disso, essa abordagem abrange também o estudo da localização espacial das atividades produtivas, especialmente as industriais.

O PNPB inovou ao assumir como objetivo explícito a promoção do desenvolvimento regional e da redução das desigualdades regionais, particularmente nas regióes Norte e Nordeste, e a inclusão social e produtiva da agricultura familiar na cadeia do biodiesel, como meio da geração de emprego e renda. Adotou, explicitamente, as preocupaçóes e o ideário do desenvolvimento regional, como elemento central da própria programa, mas fora dos marcos institucionais e instrumentais adotados pelos programas de desenvolvimento regional adotados no passado (GARCIA, 2007; CUNHA, 2011; SAMPAIO, 2017; COSTA, 2017).

Dessa forma, o PNPB é um programa abrangente que contempla diversas dimensóes, em particular a política, econômica, social e ambiental, cuja implementação requer o concurso de um grande conjunto de instrumentos e instituições cuja mobilização e envolvimento são necessários para garantir o alcance das metas de produção e uso do biodiesel. A garantia de êxito do Programa é desafiadora, especialmente considerando os objetivos inovadores e ambiciosos de inclusão social dos agricultores familiares e o estímulo ao desenvolvimento regional.

15 anos desde sua criação em 2005 ainda é pouco a que o PNPB alcance plena maturidade, mas já é tempo suficiente para a realização de diversos estudos sobre o desempenho do Programa, seus impactos iniciais nas regióes e na agricultura familiar, problemas, desafios, aprendizado. No final de 2018 estavam em operação no território brasileiro 51 usinas produtoras de biodiesel autorizadas pela a ANP para exercer a atividade, distribuídas em todas as regióes do país e tendo uma capacidade produtiva instalada total de 8,5 milhões de $\mathrm{m}^{3}$ /ano de biodiesel (Tabela 1 ). Nota-se que aproximadamente $50 \%$ das agroindústrias de esmagamento estão concentradas no CentroOeste, região que também concentra a produção de grãos - especialmente a soja ${ }^{1}$. Também se destaca a Região Sul, que apesar de ter apenas $1 / 4$ das usinas, tem capacidade produtiva equivalente à da região Centro-Oeste. Essas duas regiôes concentram mais de $75 \%$ de capacidade produtiva instalada no Brasil, percentual que sobe para 90\% com a inclusão da Região Sudeste. Em contrapartida, as Regiões Norte e Nordeste - que são focos das açóes do PNPB -, 
têm baixa participação na cadeia agroindustrial do biodiesel, com apenas 3 usinas em cada região e $10 \%$ da capacidade produtiva brasileira total.

O conteúdo social, nos termos indicados pelo $\mathrm{PNPB}$, ou seja, a inclusão da agricultura familiar, é observado pela quantidade de usinas com certificação social definida pelas regras do SCS. Percebe-se, na Tabela 1, que mais de $75 \%$ das usinas estão credenciadas com SCS e, portanto, cumprem com a função social nos termos estabelecidos pelo Programa.

Tabela 1 - Configuração tecnológica das usinas de biodiesel autorizadas nos Estados brasileiros em 2018

\begin{tabular}{l|r|r|r|c|c|c|c}
\hline \multirow{2}{*}{ Região } & \multirow{2}{*}{$\begin{array}{c}\text { Cap. } \\
\text { Produtiva } \\
\left(\mathrm{m}^{3} / \mathrm{ano}\right)\end{array}$} & \multirow{2}{*}{$\begin{array}{c}\text { Usinas } \\
(\%)\end{array}$} & $\begin{array}{c}\text { SCS } \\
(\%)\end{array}$ & Esmagadora & $\begin{array}{c}\text { Destilaria } \\
\text { de Glicerina }\end{array}$ & Esterificação & $\begin{array}{c}\text { Trans. } \\
\text { Ferroviário }\end{array}$ \\
\cline { 6 - 9 } Norte & 349.560 & 5,9 & 2,0 & 0,0 & 0,0 & 0,0 & 0,0 \\
\hline Nordeste & 613.847 & 5,9 & 5,9 & 2,0 & 0,0 & 0,0 & 0,0 \\
\hline Sudeste & 993.996 & 15,7 & 11,8 & 2,0 & 2,0 & 2,0 & 0,0 \\
\hline Sul & 3.249 .479 & 25,5 & 23,5 & 17,6 & 5,9 & 3,9 & 5,9 \\
\hline Centro-Oeste & 3.332 .326 & 47,1 & 35,3 & 15,7 & 2,0 & 9,8 & 7,8 \\
\hline Brasil & 8.539 .207 & 100 & 78,4 & 37,3 & 9,8 & 15,7 & 13,7 \\
\hline
\end{tabular}

Fonte: Elaborado pelo autor a partir dos dados da ANP (2019), BIODIESELBR (2019a) e MAPA (2019).

Ao avaliar a capacidade produtiva instalada, observa-se no Gráfico 1 que a produção de biodiesel cresceu a cada ano, desde o início do programa. Vale destacar que em $2005^{2}$, início das atividades do PNPB, de acordo com os dados da ANP (2019), a produção de biodiesel foi de $736 \mathrm{mil} \mathrm{m}^{3}$ e já a partir de 2008 alcançou e superou 1 milhão de $\mathrm{m}^{3}$. O crescimento continuado é resultado das políticas de incentivo ao uso do biodiesel, que estabeleceu a obrigatoriedade legal da mistura do biocombustível ao óleo diesel. 2016 foi o único ano que registrou uma leve retração no crescimento, de 3,45\%, um reflexo direto da retração registrada na atividade econômica no Brasil. De forma geral, a produção de biodiesel entre os anos 2009 e 2018 teve uma taxa de crescimento médio anual de $12 \%$.

Entre as regiốes, Centro-Oeste e $\mathrm{Sul}^{3}$ têm maior participação de produção, resultado dos investimentos em máquinas e equipamentos para a implementação agroindustrial e também da oferta de grãos, especificamente a soja, que tem o óleo como um coproduto e teve maior aproveitamento e valoração com a criação do mercado do biodiesel. Os principais estados produtores são Mato Grosso e Goiás, no Centro-Oeste, Rio Grande do Sul e Paraná, na Região Sul, que juntos respondem por $75 \%$ da produção. 
São justamente esses estados que passaram por um grande processo de desenvolvimento agrícola e se consolidaram como grandes produtores de grãos com a instalação de eixos dinâmicos agroindustriais. O Sudeste tem como principais produtores os estados de São Paulo e Minas Gerais.

Nas Regiôes Norte e Nordeste a produção é inexpressiva, a despeito de serem foco do PNPB, que tem como um dos objetivos explícitos promover o desenvolvimento regional e a inclusão social por meio da cadeia do biodiesel. No Norte o principal produtor é o Tocantins, seguido de Rondônia e do Pará. O estudo de Cardoso (2014) demonstrou que a estrutura operacional da produção é deficitária e ineficaz, o que explica o baixo desempenho do PNPB a despeito dos incentivos.

A Região Nordeste já teve como produtores os estados do Maranhão, Piauí e Rio Grande do Norte. No entanto, em 2018 os únicos estados com usinas autorizadas pela a ANP eram o Ceará e Bahia, sendo esse o principal produtor da região e o 5 o maior do país. Silva et al. (2016) mostraram que na Bahia a agricultura patronal e a agricultura familiar estão integradas na cadeia do biodiesel. Destacam ainda que as experiências de aquisição de mamona e palma produzidas pela agricultura familiar não foram exitosas. Além disso, a produção de soja do estado é quase toda direcionada para a exportação, e as usinas de biodiesel têm utilizado oleaginosas de outros estados para atender a demanda. Essa condição pode representar a oportunidade para a Bahia introduzir oleaginosas alternativas à soja de forma competitiva e compatíveis com integração da agricultura familiar.

Gráfico 1 - Produção de biodiesel (B100) no Brasil por Região, em milhões de $\mathrm{m}^{3}$, e taxa de crescimento em porcentagem entre os anos 2009 e 2018

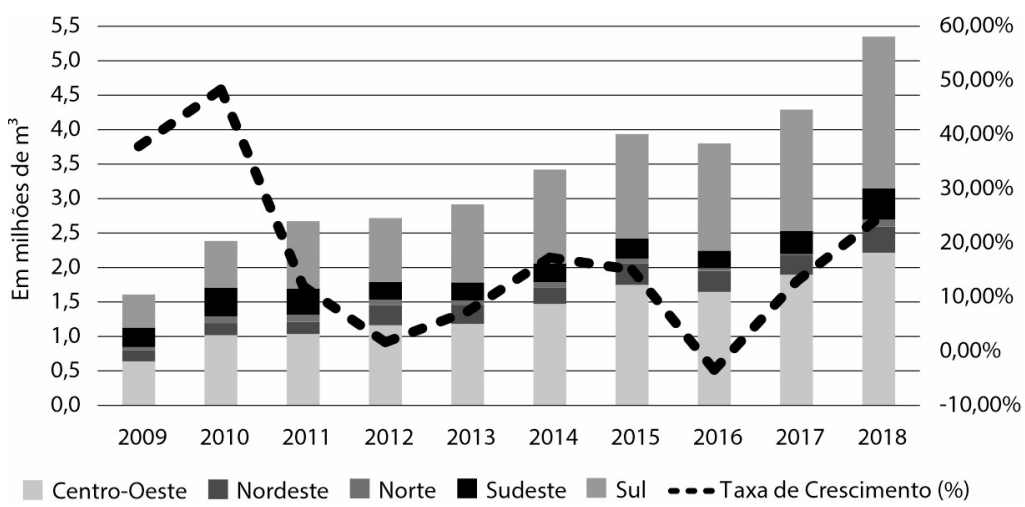

Fonte: Elaborado pelo autor a partir dos dados da ANP (2019). 
A capacidade produtiva cresceu, mas a ociosidade entre os 2005 e 2018 foi sempre elevada. Observa-se (Gráfico 2) que as usinas de processamento de biodiesel autorizadas pela a ANP e instaladas no Brasil operam com uma elevada ociosidade, associada principalmente ao crescimento lento do consumo de diesel devido à desaceleração e posterior crise da economia brasileira. Em 2005, ano inicial efetivo do PNPB, o nível de ociosidade foi de 99\%, e desde então tem decrescido, com 37\% em 2018. No período 2005-2018, em média as usinas operaram com $65 \%$ de ociosidade. Isto indica que o incentivo para a expansão da capacidade agroindustrial -principalmente via Banco Nacional de Desenvolvimento Econômico e Social (BNDES) para aquisição de máquinas e equipamentos - não foi acompanhado de um planejamento adequado para assegurar a absorção da produção de biodiesel ao consumo. Todavia, o Brasil possui uma estrutura de oferta significativa para introduzir o biodiesel na matriz energética.

Gráfico 2 - Capacidade Instalada e Produção de Biodiesel, em milhões de $\mathrm{m}^{3}$, e Capacidade Ociosa em porcentagem no Brasil entre os anos 2005 e 2018.

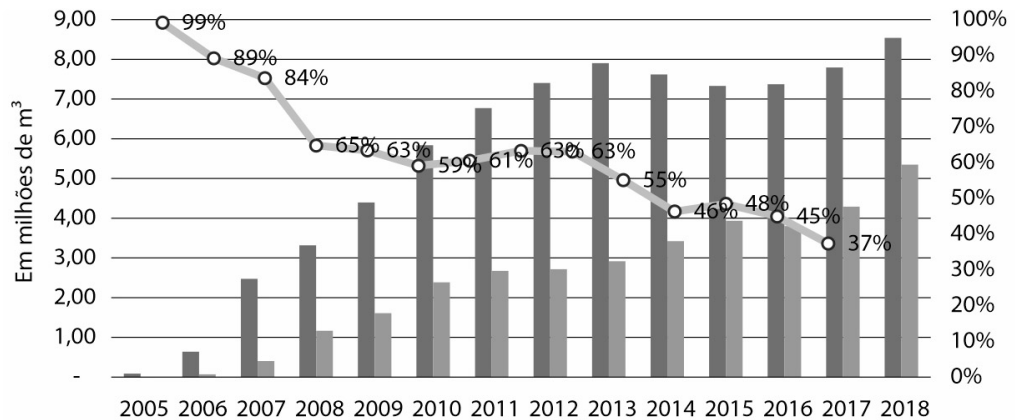

Capacidade instalada ( $\left.\mathrm{m}^{3} / \mathrm{ano}\right)$ - Produção de Biodiesel ( $\mathrm{m}^{3} / \mathrm{ano}$ ) - Capacidade Ociosa (\%) Fonte: Elaborado pelo autor a partir dos dados da ANP (2019).

As regiôes com menores níveis de ociosidade são o Centro-Oeste, Sul e Nordeste, enquanto a Região Norte mantém um nível de capacidade ociosa elevada, demonstrando que as usinas dessas regióes não conseguiram se inserir efetivamente no mercado do biodiesel e a necessidade de reformulação das políticas públicas de desenvolvimento regional para introduzir adequadamente essa região no eixo do biodiesel do Brasil com enfoque para a inclusão da agricultura familiar (Gráfico 3). 
Gráfico 3 - Capacidade Instalada e Produção de Biodiesel, em milhões de $\mathrm{m}^{3}$, e Capacidade Ociosa em porcentagem nas Regiões brasileiras no ano de 2018

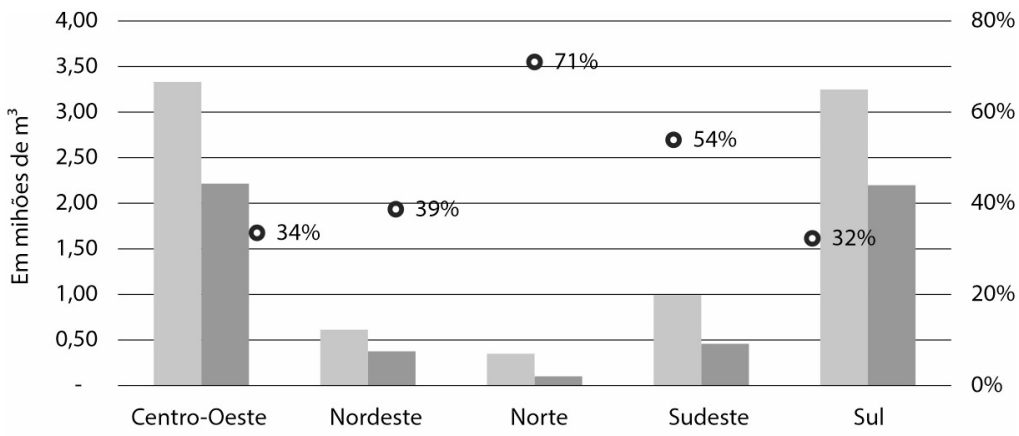

Capacidade Instalada ( $\left.\mathrm{m}^{3} / \mathrm{ano}\right)$ Produção de Biodiesel ( $\left.\mathrm{m}^{3} / \mathrm{ano}\right)$ - Capacidade Ociosa (\%)

Fonte: Elaborado pelo autor a partir dos dados da ANP (2019).

Nesse aspecto, do ponto de vista de capacidade produtiva industrial, no início de 2019 o Brasil apresentava capacidade de esmagamento e transesterificação instalada para produzir o biodiesel exigido para atender à demanda nacional, mesmo supondo um crescimento robusto do consumo de diesel. Por outro lado, um dos grandes desafios para a ampliação da produção e utilização do biodiesel é assegurar a oferta de matérias-primas a preços competitivos. De fato, os principais entraves estão "antes e dentro da porteira" (CASTRO, LIMA, SILVA, 2010). A concentração da produção, se de um lado facilitou os investimentos que viabilizaram o rápido crescimento da produção, por outro onera a logística de distribuição do diesel na ponta do consumidor.

O crescimento e dinâmica da cadeia produtiva do biodiesel têm sido fortemente marcados pelas regras, incentivos e açóes estipuladas e executadas no contexto do PNPB, juntamente com regras específicas associadas ao desenho e governança do mercado de biodiesel. Nota-se que esse setor vem se fortalecendo justamente nas regióes com produção agropecuária mais dinâmica, que coincidem com o nível de desenvolvimento mais elevado.

À luz das informaçóes disponíveis, pode-se afirmar que a elevada concentração da capacidade produtiva não é coerente com o objetivo do Programa de promover o desenvolvimento regional nas regióes menos desenvolvidas, especificamente Norte e Nordeste. As hipóteses são claras e não excludentes: de um lado, a base agropecuária e a experiência em termos organizacionais, técnicos e produtivos das cadeias agroindustriais já instaladas em regiôes tradicionalmente agrícolas (Centro-Oeste e Sul) e industrializadas (Sudeste) moldaram a montagem e expansão da cadeia de 
biodiesel. De outro, os instrumentos utilizados pelo PNPB, a despeito de manterem os objetivos originais do Programa, foram de fato usados com a preocupação primeira de assegurar o suprimento de biodiesel, na prática relegando para plano secundário os objetivos de desenvolvimento regional e inclusão produtiva.

As evidências disponíveis permitem sustentar que a evolução do Programa foi pautada claramente pela coordenação de mercado, e não pelas políticas públicas que incluem formalmente objetivos de desenvolvimento regional e inclusão produtiva. O mercado promoveu as regióes mais desenvolvidas, que já contavam com fontes de matérias-primas como a soja e a gordura animal, que ofereciam, no ponto de partida e no curto prazo, vantagens competitivas para os empreendedores que atuam neste segmento. Mais ainda, as políticas aplicadas contribuíram para reforçar a coordenação de mercado, sem buscar de fato canalizar incentivos para criar condições para a emergências de desenhos alternativos e competitivos. Portanto, a concentração de usinas instaladas em regiôes de alto desenvolvimento resultou na distorção dos objetivos do programa que levaram a impactos pequenos nas regiôes menos desenvolvidas.

\section{PANORAMA DO SELO COMBUSTÍVEL SOCIAL}

Diante dos incentivos iniciais feitos pelo Programa, diversas usinas foram instaladas nas diferentes regióes brasileiras. A Figura 1 mostra a distribuição dos produtores de biodiesel no Brasil, destacando a concentração de usinas no eixo Centro-Sul, onde a cadeia produtiva da soja está bem consolidada. Ou seja, como bem estabelecido pela teoria (LIMA, 2006), os produtores de biodiesel buscaram se instalar em localidades com maior viabilidade de acesso a esta matéria-prima. A Região Norte conta com apenas três usinas, a despeito de ser uma região foco para o Programa, seja no âmbito dos objetivos de desenvolvimento regional seja no de diversificação das fontes de matéria-prima. A Região Nordeste acompanha o mesmo padrão da Região Norte e apresenta também apenas três usinas, destacando-se que duas delas são resultado de investimentos da Petrobrás Biocombustíveis, situadas nos municípios de Candeias e Quixadá, nos estados da Bahia e Ceará, respectivamente.

A Petrobrás Biocombustíveis também tem uma unidade instalada no município de Montes Claros no estado de Minas Gerais e teve o experimento de uma unidade no município de Guamaré no estado do Rio Grande do Norte, porém, a usina potiguar não se estabeleceu. A proposta de instalação de usinas da Petrobrás Biocombustíveis nestas localidades é uma clara 
medida de proposição de um modelo de desenvolvimento regional no semiárido brasileiro a partir da ação Estatal, conforme estabelecido por Amaral Filho (2001), que indica a importância do planejamento e ação do Estado para a melhoria das condiçôes de desenvolvimento em uma região.

Entretanto, Sampaio (2017) avaliou a experiência da Petrobrás Biocombustível para promover a inclusão de agricultores familiares e a diversificação das matérias-primas pelo prisma das capacidades estatais, e concluiu que a empresa não foi capaz de elaborar estratégias inovadoras e com força suficiente para modificar os fatores estruturais que limitam a participação da agricultura familiar, e nem tampouco para superar as lacunas deixadas pelos instrumentos e mecanismos adotados pelo PNPB. Em específico a unidade de Guamaré, a planta experimental tinha o objetivo de produzir biodiesel à base de mamona e intensificar açóes relacionadas à rede pesquisa em bioprodutos $^{5}$; no entanto, as dificuldades encontradas para organizar a produção e oferta de mamona e a mudança de objetivos da Petrobrás a partir de 2015, priorizarando a eficiência operacional em detrimento, levaram à desativação da usina.

O mapa indica as usinas que obtiveram o Selo Combustível Social. Percebe-se que a maioria dos produtores de biodiesel são certificados com o SCS, que exige a aquisição de um percentual mínimo - estabelecido por lei de matéria-prima proveniente da agricultura familiar. Porém, parte considerável das usinas credenciadas com o SCS encontra-se justamente nas regióes do Centro-Oeste, onde a base de agricultores familiar é mais reduzida, e Sul, que conta com forte presença da agricultura familiar na matriz produtiva da agricultura. Especificamente na Região Sul, a agricultura familiar mais consolidada apresenta condiçóes estruturais - conhecimento, experiência, capacitação - que viabilizamsua inserção em diversos segmentos dinâmicos, inclusive na cadeia agroindustrial do biodiesel. A Região Norte, por outro lado, tem apenas uma usina com Selo, reflexo das dificuldades para obter matéria-prima suficiente para atender os requisitos de proporção mínima. Deve-se destacar que nessa região o perfil da agricultura familiar não favorece sua inclusão na cadeia de biodiesel baseada no óleo de soja e na gordura animal.

A partir dos dados do MAPA (2018), a Tabela 2 apresenta o número de famílias da agricultura familiar que fornecem matéria-prima para os produtores de biodiesel credenciados com o SCS, entre os anos 2009 e 2018. Percebe-se que o número de famílias fornecedoras cresceu nos anos iniciais do Programa, entre 2009 e 2011, possivelmente devido ao engajamento das instituiçóes responsáveis pelo Programa, o interesse das usinas em usufruir dos benefícios do SCS e, principalmente, devido ao entusiasmo das 
Figura 1 - Distribuição das plantas agroindustriais de biodiesel no Brasil em 2018.

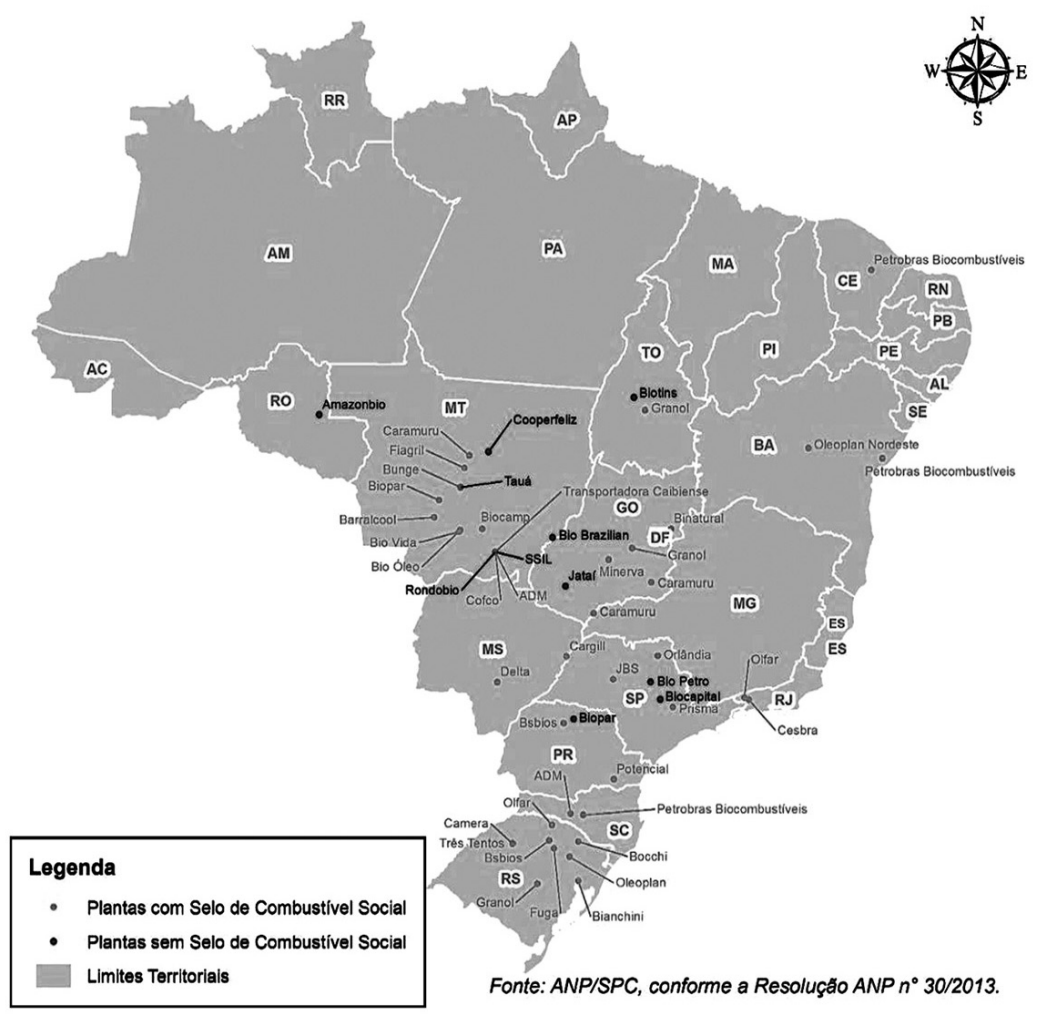

Fonte: Elaborado pelo autor a partir dos dados da ANP (2019) e MAPA (2019).

famílias com a possibilidade de se inserirem em uma nova atividade produtiva. Buainain e Batalha (2007) constataram que aproximadamente 20 mil unidades familiares produtoras de culturas oleaginosas se situavam nas regióes Norte e Nordeste e estavam inseridas na cadeia de biodiesel em 2005, e estimaram que até 2006 atingiria 100 mil e em 2007 chegaria 250 mil.

No entanto, desde o ano de 2012 o número de famílias fornecedoras vem diminuindo, o que reflete um processo de seleção dos agricultores familiares em função das condiçóes estruturais de logística, sociais, econômicas, ambientais, políticas, institucionais e organizacionais. Esta seleção pode ser evidenciada pelo predomínio da Região Sul na inclusão de um maior número de famílias inseridas no Programa, mesmo em um período no qual se observa a queda geral do número de agricultores familiares. 
Conforme Garcia (2007), os aspectos estruturais diferenciados entre as regiôes Sul e Nordeste são decisivas para viabilizar a inserção da agricultura familiar. No início do Programa, impulsionado pelos incentivos da política pública que carreou investimentos para o Nordeste, a produção de biodiesel e o número de famílias inseridas cresceu na região. No entanto, a partir de 2012 a tendência foi de redução e em 2017 a participação era quase nula. Trata-se, sem dúvida, do resultado das dificuldades produtivas encontradas pela agricultura familiar nessa região e da ausência de açôes para superar essas dificuldades e criar condições para a inserção sustentável dos familiares tendo como base outras fontes de óleo que não a soja e o sebo animal. $\mathrm{Na}$ Região Norte, que também era uma das regióes focos do Programa no objetivo de promoção de desenvolvimento regional, a participação da agricultura familiar sempre foi bastante limitada, apontando que os incentivos oferecidos pelo SCS foram insuficientes para estimular as usinas produtoras a contratar o fornecimento de matéria-prima com esse segmento de produtores.

Vale destacar que para cumprir as cotas mínimas determinadas pela legislação e obter as vantagens do Selo, algumas agroindústrias adquirem a produção agrícola de oleaginosas proveniente de agricultores familiares em estados situados em regióes diferentes de onde estas usinas estão instaladas. Em alguns casos, a matéria-prima sequer é transportada e utilizada no processo produtivo de biodiesel e comercializada pelas empresas para outros fins, especialmente para exportação ou estocada e revendida para outras usinas mais próximas em um momento oportuno (CÉSAR, 2009; FREITAS, LUCON, 2011; FROZZA, TATSCH. 2014).

Dessa forma, estados como Alagoas e Sergipe, que não contam com usinas produtoras de biodiesel, estão registrados como fornecedores de "matérias-primas” por famílias da agricultura familiar para empresas de fora, em um processo pouco claro cuja racionalidade econômica precisa ser melhor compreendida. É provável que a exigência do SCS justifique e exija que as empresas de biodiesel mantenham o Selo a despeito do elevado custo de transação para sua obtenção, e que seja mais rentável manter as vantagens adquiridas pela concessão do Selo do que operar sem ele.

Uma das questóes consideradas por Ribeiro et al. (2018) como distorções do Selo Combustível Social é a aquisição de matéria-prima, especificamente a soja, por usinas de biodiesel situadas no Centro-Oeste, de agricultores familiares do Sul. Os produtores de biodiesel sulistas apontaram que a compra obrigatória de oleaginosas da agricultura familiar gerou uma externalidade negativa no mercado, uma vez que estimulou as empresas de biodiesel do Centro-Oeste a demandarem matéria-prima do Sul, que desencadeou uma competição maior e resultou na inflação do mercado local. A Região 
Sul é onde existe o maior número de cooperativas de agricultores familiares e um nível de desenvolvimento tecnológico mais elevado. Entretanto, essa prática adotada pelas usinas do Centro-Oeste implica em uma contradição do PNPB, tendo em vista que não contribui para o desenvolvimento local da região por meio da melhoria de renda dos agricultores familiares.

Em relação ao valor gerado a partir da comercialização de matéria-prima da agricultura familiar, observa-se um crescimento considerável entre 2008 e 2018, chegando a movimentar mais de 4 bilhóes de reais no ano de 2016. Em 2017, além da redução da quantidade de matéria-prima fornecida, houve também uma redução no preço da soja no comércio internacional, o que refletiu nos preços praticados no mercado doméstico brasileiro e também expressa a pouca valorização de outras oleaginosas utilizadas no processo produtivo do biodiesel.

Como resultado da participação significativa de famílias na comercialização de matérias-primas e do elevado volume de toneladas das regióes Sul e Centro-Oeste, o valor de produção movimentado entre os anos se concentra nestas regióes, entrando em desacordo com os objetivos sociais estabelecidos pelo PNPB. Enquanto no Norte e Nordeste as atividades agrícolas associadas ao fornecimento de oleaginosas para as usinas de biodiesel não geraram valores significativos de renda (ISOLANI \& TONIN, 2013). Vale destacar que em 2018 houve uma retomada na quantidade de famílias, volume e valor de matéria-prima comercializada, porém, puxada notadamente pela Região Sul, em específico, o estado do Rio Grande do Sul.

A redução acentuada no número de famílias fornecedoras de matériaprima entre 2008 e 2017 não se traduziu em redução na quantidade de matéria-prima oriunda da agricultura familiar, que teve aumento significativo no mesmo período, com exceção dos anos de 2016 e 2018, em função da recessão econômica que atingiu a economia brasileira de modo abrangente, inclusive o setor produtor de biodiesel, e resultou na redução da demanda de matéria-prima de forma geral (Tabela 2).

Esse contraste entre a redução do número de famílias fornecedoras e o aumento do volume de matéria-prima fornecida à cadeia produtiva do biodiesel revela a seleção de agricultores familiares com maior escala de produção e produtividade mais elevada. Ou seja, também na cadeia do biodiesel está ocorrendo o processo de seleção dos agricultores mais competitivos observado nas cadeias avícola, suína, flores e lácteo, que tende a deslocar os familiares com menor escala e com localização desfavorável (BUAINAIN, 2007).

Percebe-se que as regióes com maior participação no volume de produção da agricultura familiar são Centro-Oeste e, especialmente, Sul, que apresentam uma organização produtiva estabelecida à base de soja. A Região Sudeste 
apresenta uma participação tímida no âmbito SCS, reflexo do baixo desempenho na agricultura, uma vez que é caracterizada de forma geral por se destacar no setor industrial. Regióes como Norte e Nordeste apresentam uma produção insignificante da agricultura familiar, mesmo depois de se passar mais de dez anos da implementação do PNPB, demonstrando que as ações do Programa ainda não foram suficientes para viabilizar a agricultura familiar nessas regiōes (SILVA et al., 2014).

Tabela 2 - Número de famílias cadastradas, volume em mil toneladas e valor em milhões de reais de matéria-prima fornecida no Selo Combustível Social entre os anos 2009 e 2018

\begin{tabular}{|c|c|c|c|c|c|c|c|c|c|c|c|}
\hline 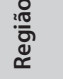 & Variável & 2009 & 2010 & 2011 & 2012 & 2013 & 2014 & 2015 & 2016 & 2017 & 2018 \\
\hline \multirow{3}{*}{$\begin{array}{l}\stackrel{0}{ \pm} \\
\text { Zे }\end{array}$} & $\mathrm{F}$ & 177 & 246 & 56 & 60 & 327 & 313 & 304 & 260 & 255 & 326 \\
\hline & Mil ton. & 14 & 17 & 9 & 9 & 9 & 8 & 11 & 3 & 2 & 27 \\
\hline & Milhão R\$ & 2 & 3 & 5 & 7 & 8 & 7 & 11 & 4 & 6 & 27 \\
\hline \multirow{3}{*}{ 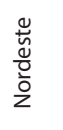 } & Famílias & 17.711 & 41.253 & 37.226 & 25.210 & 12.949 & 4.757 & 3.926 & 1.923 & 485 & 556 \\
\hline & Mil ton. & 24 & 33 & 7 & 1 & 1 & 3 & 9 & 32 & 54 & 53 \\
\hline & Milhão R\$ & 27 & 47 & 7 & 0,6 & 1,2 & 4 & 13 & 49 & 72 & 83 \\
\hline \multirow{3}{*}{ 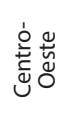 } & $\mathrm{F}$ & 2.550 & 3.388 & 3.533 & 4.513 & 5.133 & 4.757 & 4.548 & 4.109 & 3.266 & 2.773 \\
\hline & Mil ton. & 280 & 442 & 429 & 560 & 603 & 543 & 531 & 480 & 373 & 383 \\
\hline & Milhão R\$ & 203 & 243 & 295 & 434 & 526 & 528 & 521 & 546 & 407 & 437 \\
\hline \multirow{3}{*}{ 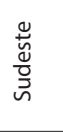 } & Famílias & 1.457 & 3.297 & 2.486 & 2.378 & 2.287 & 1.837 & 1.818 & 1.040 & 474 & 433 \\
\hline & Mil ton. & 2 & 66 & 69 & 101 & 130 & 94 & 130 & 85 & 42 & 44 \\
\hline & Milhão R\$ & 22 & 42 & 54 & 93 & 130 & 98 & 137 & 98 & 47 & 48 \\
\hline \multirow{3}{*}{$\bar{\Xi}$} & Famílias & 29.152 & 52.187 & 60.994 & 60.512 & 63.058 & 61.815 & 61.889 & 62.923 & 55.429 & 57.895 \\
\hline & Mil ton. & 511 & 1.094 & 1.398 & 1.534 & 2.051 & 2.385 & 2.801 & 2.717 & 2.585 & 3.400 \\
\hline & Milhão R\$ & 424 & 723 & 1.157 & 1.576 & 2.190 & 2.615 & 3.260 & 3.577 & 2.970 & 4.581 \\
\hline
\end{tabular}

Fonte: Elaborado pelo autor a partir dos dados do MAPA (2018).

No tocante à produtividade da agricultura familiar, o Gráfico 4 mostra a quantidade de matéria-prima média por família fornecida às usinas de biodiesel com SCS nas regióes brasileiras. Observa-se que a Região CentroOeste apresenta uma produtividade média elevada de forma constante durante o período de 2008 a 2018, demonstrando que mesmo a soja sendo uma commodity característica do agronegócio brasileiro ainda tem compatibilidade produtiva com a estrutura agrária da produção familiar dessa região. A Região Sudeste também se destaca ao se considerar o número reduzido de famílias e de volume de produção comercializada nos moldes do SCS. 
Os agricultores familiares da Região Sul, por sua vez, apresentam uma produtividade média baixa comparando com essas regióes, uma vez que é no Sul onde encontra-se o maior número de famílias e também de volume de produção.

A Região Norte, entre os anos 2008 e 2012, apresentou uma produtividade média de matéria-prima elevada em comparação às demais regióes, porém, isso foi resultado do baixo número de famílias envolvidas na cadeia produtiva do biodiesel e não significa que houve uma produção elevada, como observado na Tabela 2. Os agricultores familiares da Região Nordeste, de forma geral, demonstraram uma produtividade insignificante, resultado das dificuldades produtivas enfrentadas por esses produtores, especialmente no Semiárido e, ainda, por não encontrarem uma oleaginosa que seja compatível com a estrutura produtiva e competitiva no mercado. Percebe-se que em 2017 ocorreu um salto de produção, para 100 toneladas, em média, de matéria-prima por agricultor familiar. Porém, isso está associado à redução significativa na quantidade de famílias de agricultores familiares fornecedores para as usinas de biodiesel, permanecendo apenas os mais competitivos da região.

Gráfico 4 - Toneladas de matérias-primas produzida, em média, por número de famílias no Selo Combustível Social entre os anos 2008 e 2018

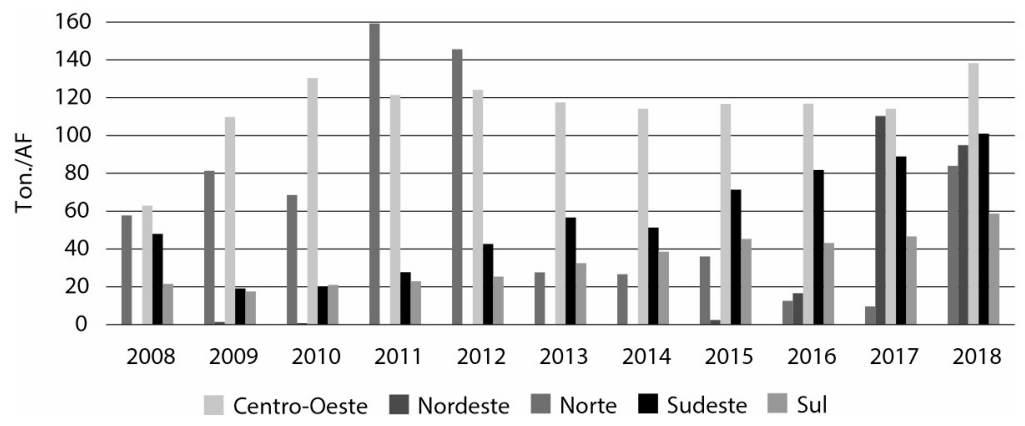

Fonte: Elaborado pelo autor a partir dos dados do MAPA (2018).

No que diz respeito ao tipo de matéria-prima fornecida pela agricultura familiar aos produtores de biodiesel com SCS, a Tabela 3 demonstra que, de forma geral, a soja é a principal oleaginosa comercializada pelas famílias de pequenos produtores em todas as regiôes brasileiras, confirmando que até mesmo no segmento produtivo da agricultura familiar a produção de biodiesel foi estabelecida à base dessa matéria-prima. No entanto, conforme Monteiro (2007), esse processo é incompatível com a proposta do PNPB de 
fomentar a diversificação de matérias-primas utilizadas no processo produtivo de biodiesel, especialmente na introdução de oleaginosas adequadas para a estrutura produtiva da agricultura familiar.

$\mathrm{Na}$ Região Nordeste e Semiárido foram utilizados alguns incentivos fiscais e creditícios para estimular os produtores de biodiesel a usar outras oleaginosas e viabilizar a diversificação no fornecimento de matérias-primas (FREITAS \& LUCON, 2011). Assim, mesmo sendo a soja a principal oleaginosa comercializada pelos agricultores familiares, observa-se maior diversificação de fontes de matérias-primas no Nordeste em comparação com as demais regiôes: especialmente os óleos de mamona, coco e dendê, que foram as principais oleaginosas incentivadas na legislação com a isenção fiscal para as usinas de biodiesel que adquirissem algum tipo de matéria-prima da agricultura familiar, estão presentes como fontes de matéria-prima utilizadas para a produção de biodiesel.

Na Região Norte, por sua vez, não se registrou o uso de outras matérias-primas para abastecer a cadeia produtiva de biodiesel. A soja continuou como a principal oleaginosa, mas o que se destaca é a presença de sebo bovino fornecido pela a agricultura familiar, o que parece entrar em choque com o perfil da agricultura familiar da região, que pratica uma pecuária pobre, atomizada e marcadamente informal. Vale lembrar que a produção pecuária de corte bovino é uma atividade econômica de grande magnitude na região Norte, com a presença de diversos frigoríficos por todo o território. Porém, dado que a criação de animais de grande porte é incompatível com a estrutura agrária de alguns produtores familiares, uma vez que a atividade extensiva demanda vastas áreas de terra, apenas alguns produtores têm a possibilidade de serem inseridos na cadeia agroindustrial de biodiesel com a comercialização de gordura bovina (MARTINS et al., 2011).

Outro entrave evidenciado para a utilização de matérias-primas alternativas à soja é a baixa competitividade, uma vez que o preço médio praticado é superior em todos os casos, chegando o sebo bovino a corresponder até oito vezes mais, pois existe outros mercados que demandam essa matéria-prima no processo industrial e pressiona o aumento de preço. César (2009) indica que a mamona e o dendê, possivelmente, tornam-se atrativos para os produtores de biodiesel por trazerem os benefícios fiscais, porém, não oferecem competitividade suficiente para substituir a soja na produção.

Tiburcio (2011) constatou que o PNPB foi resultado de dinâmicas e consequências políticas mais amplas, objetivando atender as demandas do setor petrolífero, fabricantes de veículos a diesel e o complexo da soja, onde surgem oportunidades para a agricultura familiar. Entretanto, o mercado estabelecido para o biodiesel ficou subordinado ao setor da soja e, por isso, 
limita a participação da agricultura familiar aos produtores especializados na produção de soja. Assim, a produção de matéria-prima para biodiesel privilegia os aspectos econômicos, em detrimento dos sociais e ambientais, o que compromete o desenvolvimento sustentável dos territórios rurais.

Destaca-se que esses dados ainda não estavam disponíveis pelo MAPA. Assim, foi necessário a formalização do pedido no Portal da Transparência para a obtenção dos resultados no ano de 2018 , que é o ano mais recente que houve a organização, processamento e disponibilização dos dados. Constatou-se também que existe uma grande diferença entre o valor médio da tonelada de sebo bovino obtido pelos produtores familiares do Norte e CentroOeste em relação ao Sul, uma vez que enquanto nas duas primeiras regióes o valor médio dessa matéria-prima correspondeu a média de $\mathrm{R} \$ 8.950,36$, na região Sul esse mesmo indicador apontou um valor médio de $\mathrm{R} \$ 1.257,72$ de tonelada do sebo bovino fornecido por agricultores familiares às usinas de biodiesel.

Tabela 3 - Matérias-primas fornecidas pela agricultura familiar no âmbito do Selo Combustível Social em 2018.

\begin{tabular}{l|l|c|c|c}
\hline \multicolumn{1}{c|}{ Região } & Matéria prima & Volume (mil ton.) & Valor (milhões R\$) & Valor médio (R\$)/Ton. \\
\hline \multirow{4}{*}{ Norte } & Dendê & 24,83 & 5,51 & 221,87 \\
\cline { 2 - 5 } & Bovino & 2,54 & 21,83 & $8.593,53$ \\
\hline \multirow{4}{*}{ Nordeste } & Soja & 38,45 & 44,99 & $1.170,13$ \\
\cline { 2 - 5 } & Coco & 10,85 & 28,12 & $2.591,88$ \\
\cline { 2 - 5 } & Mamona & 3,21 & 9,61 & $2.997,23$ \\
\cline { 2 - 5 } & Óleo de dendê & 0,26 & 0,73 & $2.790,74$ \\
\hline \multirow{3}{*}{ Sudeste } & Bovino & 0,07 & 0,61 & $9.307,19$ \\
\cline { 2 - 5 } & Soja & 383,41 & 436,11 & $1.137,45$ \\
\hline \multirow{3}{*}{ Sul } & Macaúba & 0,01 & 0,02 & $2.344,00$ \\
\cline { 2 - 5 } & Soja & 43,74 & 48,40 & $1.106,67$ \\
\hline & Canola & 4,66 & 5,44 & $1.166,70$ \\
\cline { 2 - 5 } & Bovino & 0,07 & 0,08 & $1.257,72$ \\
\cline { 2 - 5 } & Soja & $3.370,13$ & $4.510,08$ & $2.597,24$ \\
\cline { 2 - 5 } & Óleo de soja & 22,01 & 57,17 & $2.500,00$ \\
\cline { 2 - 5 } & Óleo de frango & 3,16 & 7,91 & \\
\hline
\end{tabular}

Fonte: Elaborado pelo autor a partir dos dados do MAPA (2018).

Portanto, percebe-se que mesmo no âmbito do Selo Combustível Social, até o final de 2018 ainda não tinha sido possível uma diversificação produtiva no abastecimento de matérias-primas para às usinas de biodiesel. 
Os instrumentos adotados na Região Nordeste indicam que é possível incluir outras oleaginosas, mas ainda não foram suficientes para substituir a soja e aponta para alternativas que passam pela esfera institucional para promover a substituição parcial ou até mesmo completa da soja nas regióes Sul, Sudeste e Centro-Oeste por meio da replicação destas políticas de incentivo fiscais direcionadas a outras oleaginosas, como ocorreu no Nordeste, o que possibilita até mesmo a diversificação da estrutura produtiva da agricultura familiar, que encontra-se também especializada na soja.

\section{A PRODUÇÃO DE BIODIESEL COM MATÉRIA-PRIMA DA AGRICULTURA FAMILIAR}

É possível avaliar a inserção da agricultura familiar na cadeia produtiva do biodiesel estimando a produção de biodiesel que utiliza matéria-prima fornecida por estes agricultores. Com base em informaçóes do MAPA, especificamente do SCS, e da ANP, foi possível estimar a produção de biodiesel produzido com matéria-prima oriunda da agricultura familiar - aqui denominada 'biodiesel familiar' ou 'biodiesel do SCS' -, e logo a participação relativa da produção de biodiesel familiar no âmbito nacional e nas diferentes regióes brasileiras.

Para estimar a quantidade de biodiesel produzido com matéria-prima da agricultura familiar adotou-se como critério o rendimento de $18 \%$ de óleo de soja por tonelada, tendo como base os trabalhos de Souza et al. (2017) e Ramos et al. (2017). ${ }^{6}$

Destaca-se que não estão disponíveis dados sobre a utilização de outras fontes de matérias-primas para os anos anteriores a 2017. No entanto, a estimativa da produção de biodiesel com matéria-prima provida pela agricultura familiar com base apenas no rendimento do óleo extraído da soja não traz grandes implicaçóes, visto que essa oleaginosa é majoritária ${ }^{7}$ mesmo no âmbito do SCS.

O Gráfico 5 apresenta os resultados dessa estimativa entre os anos 2008 e 2018. Percebe-se que, assim como a produção de biodiesel cresceu expressivamente devido aos sucessivos aumentos na mistura obrigatória de biodiesel ao óleo diesel e do consumo de diesel, o biodiesel certificado pelo SCS também acompanhou o crescimento da produção de biodiesel em geral, o que foi possível especialmente devido às alteraçóes realizadas nos parâmetros mínimos do Selo para aquisições de matéria-prima pelas usinas e, desta forma, facilitou a certificação do SCS.

No plano regional, observa-se a posição de destaque da produção de biodiesel familiar no Sul, onde a agricultura familiar é mais forte, mais 
integrada às cadeias produtivas de grãos, apresenta nível elevado de organização e conta com infraestrutura logística para atender as linhas de suprimento das usinas, conforme Garcia (2007) e é representado especialmente pelo estado do Rio Grande do Sul. O crescimento da produção de biodiesel do SCS foi alavancado pelo estado gaúcho, com dinâmica bem diferente da maioria dos estados. Por outro lado, a presença do agronegócio é marcante na economia do Centro-Oeste, caracterizada por produção em larga escala (FIGUEIREDO, 2003) e pequena participação da agricultura familiar, resultando em uma produção de biodiesel familiar sem avanços expressivos.

Em relação às condiçôes estruturais de Mato Grosso, que é o segundo maior produtor de biodiesel no Brasil, Alves et al. (2012) avaliaram a produção agrícola em assentamentos do estado e constataram que a infraestrutura instalada é uma das principais responsáveis pela ineficiência produtiva dos produtores assentados. Esses entraves estruturais se refletem na logística do conjunto de agricultores familiares mato-grossenses e, consequentemente, nas condições produtivas e na possibilidade de inserção em uma cadeia exigente como a do biodiesel.

A estrutura agrária é um dos fatores que limita o cultivo da soja pelos familiares que possuem em média pouca terra para um cultivo nos quais as possibilidades de ganhos de escala são expressivas (HIRAKURI et al. 2018; WESZ JUNIOR \& GRISA, 2017). Nesse sentido, Rodrigues (2015) avaliou em seu trabalho a relação da agricultura familiar e o PNPB no norte do Mato Grosso, e identificou que para os próprios agricultores familiares é clara a importância dos ganhos de escala nos rendimentos auferidos a partir do uso dos mesmos pacotes tecnológicos. Assim, as condições estruturais e produtivas da agricultura familiar refletem-se na retração da produção de biodiesel familiar mato-grossense.

Quanto às demais regióes, Leite et al. (2013) apontam que é fundamental o reconhecimento da heterogeneidade da agricultura familiar em termos de estrutura e sistemas agrícolas para compreender a capacidade e disposição de engajamento dos agricultores na produção e fornecimento de matéria-prima para a cadeia do biodiesel, o que deve ser considerado no processo de elaboração de políticas. A maioria dos agricultores nas diferentes regióes brasileiras encontram imensos desafios para se inserirem nos mercados de biodiesel. Os principais entraves constatados estão relacionados a açốes coletivas enfraquecidas, ao baixo acesso a insumos e às limitaçóes de mercado e dos fatores de produção (capital, terra e mão de obra), especialmente para a agricultura familiar do Semiárido, onde tiveram incentivos para a produção de mamona, porém, ocorreu um baixo envolvimento dos agricultores para o cultivo desta cultura devido o desconhecimento das restriçóes identificadas no estudo. 
As dificuldades produtivas evidenciadas se repetem para os agricultores familiares da região Sudeste, o que explica a inexpressiva produção de biodiesel familiar nessas regióes.

$\mathrm{O}$ enfraquecimento da produção de biodiesel via agricultura familiar entra em desacordo com os objetivos de inclusão social e promoção do desenvolvimento regional. De um lado, não resulta em impactos significativos para a geração de emprego e renda dos agricultores familiares das regióes focos do Programa, Norte e Nordeste, e das regióes pautadas no agronegócio e na industrialização, como Centro-Oeste e Sudeste. De outro lado, seleciona apenas os produtores familiares mais rentáveis, que, em sua maioria, concentram-se na região Sul do país, onde já apresenta um modelo de desenvolvimento agrícola consolidado com a inclusão da agricultura familiar em outras cadeias. Assim, os impactos do PNPB na economia local e regional concentraram-se nos estados sulistas, indicando que os efeitos estão associados às condiçóes estruturais das regióes.

Gráfico 5 - Estimativa da produção de biodiesel produzido com matéria-prima da agricultura familiar no Brasil entre os anos 2008 e 2018.

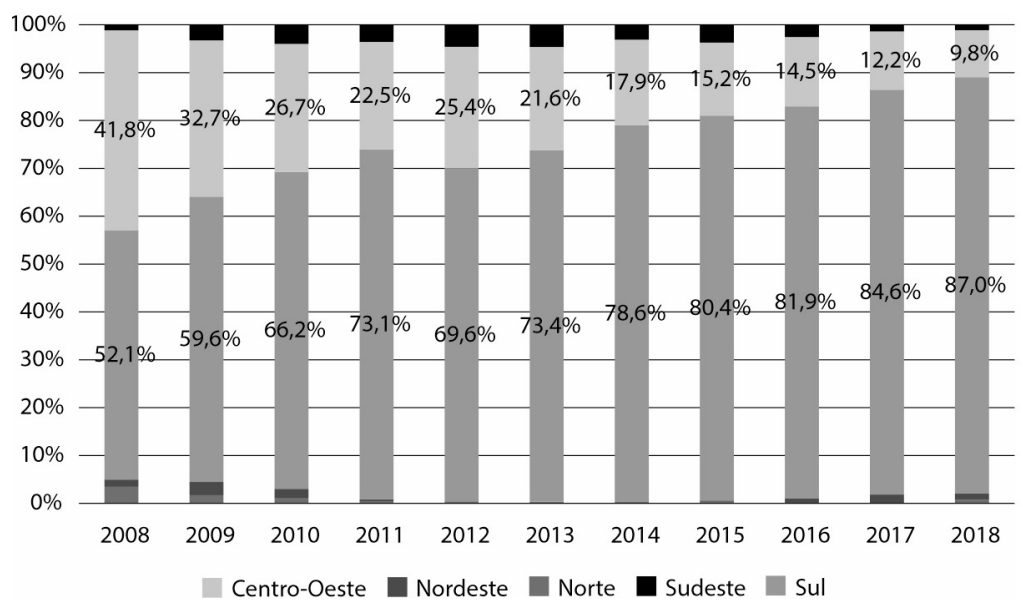

Fonte: Elaborado pelo autor a partir dos dados do MAPA (2018).

Em relação à participação relativa da produção de biodiesel do SCS, o Gráfico 6 demonstra a superioridade e a importância da Região Sul. Constatou-se que em todos os anos do período 2008-2018 essa região foi responsável por mais da metade do volume produzido de todo o biodiesel produzido no Brasil com matéria-prima proveniente de agricultores familiares, chegando, a partir de 2013, a corresponder mais de $75 \%$ da produção. Vale destacar que a 
concentração da produção está no Rio Grande do Sul, que registrou mais de 60\% da produção de biodiesel familiar no ano de 2018.

Embora o Centro-Oeste seja o segundo maior produtor de biodiesel no país, a produção de biodiesel familiar não se consolidou, demonstrando uma constante redução de participação no período. Já a produção das regiôes Norte, Nordeste e Sudeste não chegaram corresponder a $5 \%$ nos anos mais recentes. Isto revela que o SCS não parece atender o objetivo institucional do $\mathrm{PNPB}$ de inclusão social e tampouco de desenvolvimento regional no Norte e Nordeste. Essa condição também expressa a heterogeneidade estrutural entre as regióes, uma vez que mesmo tratando-se das duas maiores regióes produtoras de biodiesel ambos apresentaram resultados diferenciados para a agricultura familiar.

Gráfico 6 - Participação percentual do biodiesel produzido com matéria-prima da agricultura familiar no Brasil entre os anos 2008 e 2018.

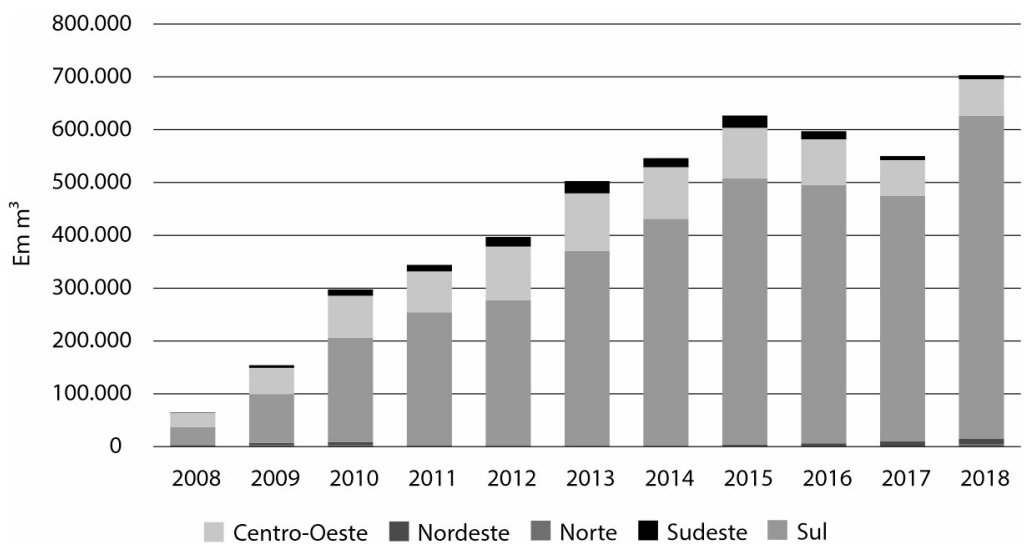

Fonte: Elaborado pelo autor a partir dos dados do MAPA (2018) e ANP (2019).

Quanto à participação percentual da produção de biodiesel familiar em relação ao volume de biodiesel produzido, o Gráfico 7 demonstra que, de modo geral, para o Brasil como um todo a parcela de biodiesel do SCS ainda é reduzida, correspondendo em média a 13\% entre os anos de 2008 a 2018. Mesmo com o aumento no volume de matéria-prima adquirida da agricultura familiar e, consequentemente, da produção de biodiesel familiar, não cresceu suficientemente para acompanhar o crescimento da produção geral de biodiesel, especialmente entre os anos 2013 e 2018. Enquanto a produção total de biodiesel cresceu na média 10,6\%, a produção de biodiesel familiar teve um aumento médio de $5,7 \%$ no mesmo período. 
Em termos regionais, o comportamento da participação relativa do biodiesel familiar apresenta diferenças consideráveis. No Sul, a produção de biodiesel com matéria-prima da agricultura familiar correspondeu em média a $27 \%$ do total entre os anos de 2008 e 2018, resultado da articulação e desenvolvimento do setor agrícola familiar na região. Por outro lado, a participação do biodiesel familiar no Centro-Oeste apresentou desempenho reduzido, e no ano de 2018 a produção foi de apenas 3\%. Nessa avaliação, até a região Norte superou as demais, demonstrando uma participação relativa de $5 \%$ nos de 2017 e 2018.

Percebe-se que, enquanto a participação de biodiesel familiar no Sul cresceu ao longo do período, a presença de biodiesel do SCS no CentroOeste apresentou sucessivas reduçôes a partir de 2013. Nos anos iniciais, a Região Norte demonstrou uma participação de quase 15\%, porém, nos anos sucessivos, acompanhou o Nordeste com participaçóes de pouca expressividade. Vale destacar que a partir de 2012, de acordo com os dados do MAPA (2018), houve uma redução acentuada no número de famílias fornecedoras de matéria-prima para as usinas. No Centro-Oeste, essa redução teve início em 2014, o que impactou na oferta de matéria-prima familiar aos produtores de biodiesel e, consequentemente, na participação da produção de biodiesel familiar.

Em relação ao baixo desempenho da participação do biodiesel familiar no Nordeste, é importante notar que esse resultado é reflexo dos problemas estruturais que não garantem competitividade e escala de produção. No ano de 2010, a região Nordeste era a segunda maior em termos de quantidade de famílias incluídas com 40 mil, atrás apenas da região Sul com 52 mil famílias. Porém, esses números não se refletiram em fornecimento de matéria-prima. Enquanto a produção de biodiesel familiar do Nordeste teve uma participação de $3,4 \%$, o Sul obteve uma participação de $29 \%$. Isso indica a baixa produtividade nordestina frente a produção agrícola sulista e a saída expressiva de agricultores familiares nos anos sucessivos, permanecendo apenas aqueles com capacidade de oferta regular.

Nesse sentido, Rodrigues (2015) confirmou que as usinas situadas no Mato Grosso encontraram dificuldades de encontrar agricultores familiares que produzam soja para atender ao requisito necessário e manter as vantagens do SCS. Assim, para manter os benefícios estabelecidos pelo Selo, as usinas competem para manter a parceria com os agricultores familiares que tem condições de produzir soja e garantir uma regularidade de entrega do produto. A forma como as usinas buscam manter a exclusividade do fornecimento dos produtores familiares, é por meio da oferta de assistência técnica e insumos para auxiliar na produção, o que é exigido pela legislação. 
Gráfico 7 - Percentual da produção de biodiesel produzido com matéria-prima da agricultura familiar no Brasil entre os anos 2008 e 2018.

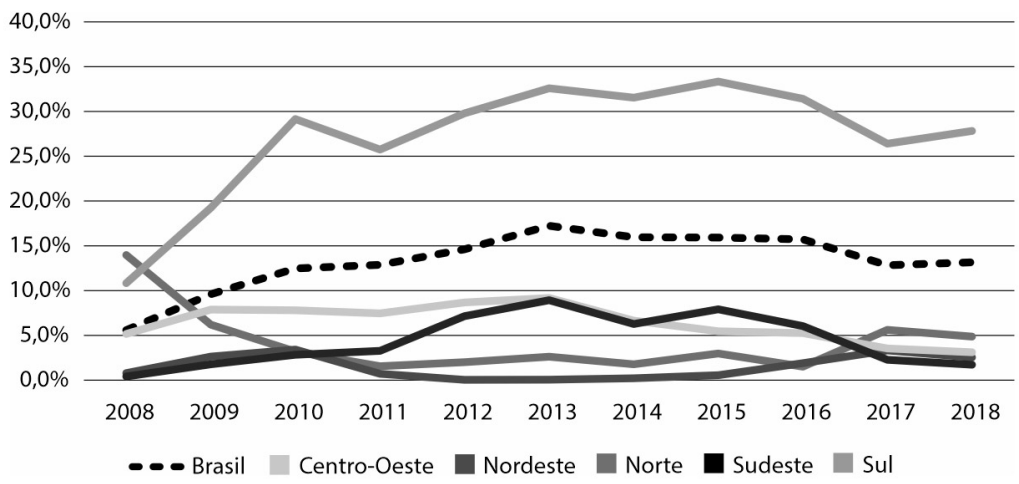

Fonte: Elaborado pelo autor a partir dos dados do MAPA (2018) e ANP (2019).

\section{CONSIDERAÇÕES FINAIS}

Diferente dos outros programas de estímulo à produção de biocombustíveis, o PNPB inovou e implementou objetivos ambiciosos de promoção do desenvolvimento regional das regióes periféricas, especialmente a Norte e a Nordeste do país, e a inclusão social por meio da agricultura familiar como fornecedora de matéria-prima; também incorporou aqueles objetivos já conhecidos de redução da dependência dos combustíveis fósseis e das emissões de GEEs. Assim, o Programa buscou encadear setores estratégicos para chegar aos objetivos propostos, conciliando a estrutura agrícola brasileira e o desenvolvimento do setor do biodiesel.

Constatou-se que a implementação do PNPB foi fundamental para a criação e consolidação da cadeia produtiva do biodiesel. O número de usinas autorizadas pelas a ANP e a capacidade produtiva cresceram e em 2018 eram de 51 e 8,5 milhôes de $\mathrm{m}^{3}$, respectivamente. Porém, percebeu-se que houve uma distorção do objetivo institucional de desenvolvimento regional, pois $47 \%$ das usinas se estabeleceram na Região Centro-Oeste e 25\% na Região Sul. Em relação à capacidade instalada, 38\% estão no Centro-Oeste e 39\% na Região Sul. Assim, mais de $70 \%$ das usinas e da capacidade instalada se concentraram nessas regióes.

A distribuição geográfica das usinas foi fundamentalmente determinada pela presença da produção de soja. Dessa forma, como essas regióes e seus respectivos estados são os principais produtores do grão, essa condição certamente contribuiu para o fortalecimento das usinas situadas nessas localidades, mostrando que a coordenação foi movida pelas forças de mercado e 
não pela ação coordenada do estado brasileiro. Isso se confirma ao olhar para a quantidade de usinas instaladas nas regióes Norte e Nordeste, que eram focos do Programa. Em especial, no Nordeste, que teve incentivos tributários diferenciados e produtivos, até mesmo com a instalação de três unidades da Petrobrás Biocombustível não foi suficiente para destacar essa região entre os principais produtores.

Além da distorção do objetivo de desenvolvimento regional resultante da ação das forças de mercado, verificou-se um descompasso entre a evolução da capacidade produtiva e o nível de comercialização do biodiesel. Em média as usinas trabalham com capacidade ociosa elevada, o que pode ser o resultado de expectativas de expansão frustrada pela desaceleração e crise da economia brasileira a partir de 2015. A capacidade instalada no final de 2019 é suficiente para atender a projeção de crescimento da demanda até 2023.

As ações do PNPB para promover a inclusão da agricultura familiar têm apresentado diferentes resultados entre as regióes e estados brasileiros. A simples concentração da produção de biodiesel é por si só uma inquestionável evidência das diferenças. A partir da análise quantitativa, foi possível identificar o nível estimado de produção de biodiesel com matéria-prima fornecida pelos agricultores familiares.

A consulta aos dados do MAPA (2018) permitiu mensurar o volume de matéria-prima do SCS fornecido para as usinas. Relacionando-o com a produção de biodiesel realizada, segundo os dados da ANP (2019), constatouse a participação relativa de produção de biodiesel via agricultura familiar. O conjunto de dados disponíveis permitiu avaliar um período de onze anos (2008 e 2018).

Além do objetivo institucional de incluir a agricultura familiar na cadeia do biodiesel, o PNPB instituiu o objetivo de incentivar a diversificação de oleaginosas, que sejam compatíveis com a estrutura agrária familiar, para o abastecimento das usinas. No entanto, inicialmente, percebeu-se que mesmo se tratando da produção agrícola familiar, com perfil de produção mais diversificado, ocorreu uma especialização no fornecimento da soja, que representou em média a $98 \%$ de toda a matéria-prima comercializada no âmbito do SCS durante o período avaliado. Esse resultado expressa uma contradição em relação às expectativas iniciais de inclusão social e diversificação das fontes de produção do biodiesel desenhadas pelo PNPB.

Como a oferta de soja é majoritária no SCS e considerando que a agricultura familiar tem uma participação pequena na produção de oleaginosa, constatou-se que, de modo geral, a produção de biodiesel familiar corresponde a uma média de $13 \%$ de todo o biodiesel produzido no Brasil entre os anos avaliados. A região Sul é a principal responsável pela produção via 
agricultores familiares, que correspondeu por mais de $85 \%$ no ano de 2018 devido à quantidade de famílias incluídas e volume de matéria-prima ofertada, reflexo do desenvolvimento agrícola e agrário da região. Ao identificar o nível estadual, observou-se que $60 \%$ da produção de biodiesel familiar se situa no estado do Rio Grande do Sul, ou seja, a rota de produção familiar está associada ao estado gaúcho.

Por outro lado, a região Centro-Oeste, que possui níveis de produção de biodiesel próximos a região Sul, e possui um modelo de desenvolvimento agrícola pautado no agronegócio, em termos de produção de biodiesel do SCS, demonstrou uma produção crescente até o ano de 2013 e nos anos seguintes apresentou sucessivas reduçóes, que chegou a corresponder uma produção de 69 milhôes de litros em 2018. Os números relativos demonstraram que a participação da produção de biodiesel familiar do Centro-Oeste passou de $41 \%$ em 2008 para $9,8 \%$ em 2018, o que demonstra a dificuldade de a agricultura familiar da região assegurar uma oferta regular de matériaprima, visto que a rentabilidade da soja depende da escala de produção.

Em específicoao segundo maior produtor de biodiesel no país, o estado do Mato Grosso, apresentou uma produção inexpressiva de biodiesel com matéria-prima do SCS durante todo o período considerado. De todo o biodiesel familiar produzido no Brasil, a produção mato-grossense correspondeu a uma média de 5\% durante o período 2008 a 2018 e mostrando uma tendência de queda, especialmente a partir do ano de 2013. Em 2018, após as sucessivas reduções, a produção mato-grossense com base no SCS respondeu por apenas $1 \%$ do biodiesel familiar produzido no país. Esta queda é explicada pelas condiçóes estruturais do estado e, especialmente, pela estrutura agrária que coloca os pequenos produtores mato-grossenses à margem do dinamismo da produção de grãos estadual, dominada por empreendimentos que operam com escala elevada.

Dado os grandes investimentos necessários, os riscos e incertezas da mudança de paradigma do setor energético no tocante a substituição de fontes de energia fósseis por renováveis, como os biocombustíveis, em especial o biodiesel, a implementação da cadeia produtiva agroindustrial do biodiesel é mediada e guiada pelas políticas públicas, em particular pela regulamentação que define o percentual da mistura e os leilóes organizados pela ANP. Ou seja, o funcionamento desse setor energético no país está atrelado à governança, organização e institucionalidade, que refletem as determinaçóes e condiçôes de operação do Estado, neste caso representado principalmente pela ANP e pelo próprio PNPB.

Portanto, a avaliação realizada revela uma ambiguidade do Estado em relação aos objetivos iniciais do Programa. De um lado, o SCS mantém-se 
como um dos pilares do Programa, e toda a regulamentação parece buscar o aperfeiçoamento deste mecanismo, que tem desempenhado um papel relevante na estratégia das empresas. De outro lado, parece haver uma acomodação em relação à consolidação da soja e do sebo bovino como fontes prioritárias de matérias-primas, assim como à geografia do biodiesel que vem sendo desenhado sob os impulsos do mercado, e que de certa forma entram em contradição com os objetivos de promoção de desenvolvimento regional e de inclusão social.

A avaliação acima confirma que o arranjo institucional do PNPB não foi suficiente para assegurar uma efetiva e expressiva participação dos agricultores na cadeia do biodiesel. Tudo indica que as restriçôes sejam de natureza mais estrutural, e que os instrumentos disponíveis no âmbito do PNPB - ofertar serviços de assistência técnica, capacitação e insumos para os pequenos produtores - são insuficientes para superá-los. No caso específico do Mato Grosso, Rodrigues e Zavala (2017) constataram que a política de estímulo da produção de matéria-prima do PNPB não implementou mecanismos adequados para possibilitar a diversificação produtiva na agricultura familiar, e que esses agricultores ficaram à mercê do mercado, em geral adverso e discriminatório.

Em resumo, o Programa não tem sido capaz de fomentar o cultivo de culturas alternativas mais viáveis para o pequeno produtor, selecionou apenas os agricultores mais capitalizados e com condições de produzir a soja em sua propriedade de forma rentável, o que explica a produção de biodiesel familiar ficar concentrada na região Sul, ser marginal na região Centro-Oeste e inexpressiva nas demais regióes. Assim, esses resultados implicam em maior geração de emprego e renda na agricultura familiar sulista em comparação com o setor agrícola familiar das outras regióes.

\section{Agradecimento \\ O presente trabalho foi realizado com apoio da Coordenação de Aperfeiçoamento de Pessoal de Nível Superior - Brasil (CAPES) - Código de Financiamento 001.}

\footnotetext{
Notas

' Principal oleaginosa utilizada no processo produtivo esmagamento e transesterificação para a obtenção do biodiesel.

2 Os resultados da produção entre os anos 2005 e 2008 foram desconsiderados no gráfico por se tratarem dos anos iniciais do PNPB, apresentando uma produção muito baixa, o que reflete em taxas de crescimento muito elevadas nos anos seguintes, que não condizem com a realidade atual da produção de biodiesel. Para exemplificar essa situação, o ano de 2006 teve um crescimento 9.273\% em comparação ao ano de 2005.

${ }^{3}$ Ver Guimarães (2017).

${ }^{4}$ Antes da porteira está associado ao fornecimento de serviços e insumos agropecuários. Dentro da porteira está ligado aos processos produtivos.
} 


\begin{abstract}
${ }^{5}$ Exemplo de lubrificantes e interações entre biomassa e produtos derivados do petróleo.
${ }^{6}$ Ou seja, de uma tonelada de soja extrai-se 180 litros de óleo vegetal e a conversão de um litro de óleo vegetal em um litro de biodiesel, conforme o estudo de Olivério et al. (2008).

${ }^{7}$ Para ilustrar essa situação, de acordo com os dados do MAPA (2018), a participação percentual da soja no SCS de valor de aquisições de matéria-prima pelas usinas correspondeu a média de 98,23\% entre os anos de 2008 e 2017.
\end{abstract}

\title{
Referências
}

ABRAMOVAY, R.; MAGALHÃES, R. O acesso dos agricultores familiares aos mercados de biodiesel: parcerias entre grandes empresas e movimentos sociais. Texto para Discussão FIPE, n. 6, São Paulo, 2007, p. 36.

ALVES, J.; FIGUEIREDO, A. M. R.; ZAVALA, A. A. Z. (In)Eficiência dos Assentamentos Rurais em Mato Grosso. Cuiabá: EdUFMT, 2012.

AMARAL FILHO, J. A Endogeneização no Desenvolvimento Econômico Regional e Local, Planejamento e Políticas Públicas. Instituto de Pesquisa Econômica Aplicada, Brasília - v. - semestral, p. 261-286, 2001.

ANP - Agência Nacional do Petróleo, Gás Natural e Biocombustíveis. Anuário estatístico brasileiro do petróleo, gás natural e biocombustivieis 2019. Agência Nacional do Petróleo, Gás Natural e Biocombustíveis. Rio de Janeiro: ANP, 2019. Disponível em: https://bit.ly/2QiISGn. Acesso em: 13 ago. 2019.

AYDALOT, P. Economic régionale et urbaine. Paris: Econômica, 1985.

BIODIESELBR. As usinas de biodiesel no Brasil. 2019. Disponível em: https://bit. ly/3indq07. Acesso em: 26 jul. 2020.

BRASIL, 2005. Lei n ${ }^{\circ} 11.116$, de 18 de maio de 2005. Dispõe sobre o Registro Especial, na Secretaria da Receita Federal do Ministério da Fazenda, de produtor ou importador de biodiesel e sobre a incidência da Contribuição para o PIS/ Pasep e da Cofins sobre as receitas decorrentes da venda desse produto; altera as Leis nos 10.451, de 10 de maio de 2002, e 11.097, de 13 de janeiro de 2005; e dá outras providências. Diário Oficial da União,
Brasília, DF, 19 mai. 2005. Disponível em: https://bit.ly/32m8ozU. Acesso em: $18 \mathrm{de}$ março de 2019 .

BUAINAIN, A. M. (Coord.). Agricultura familiar e inovação tecnológica no Brasil: características, desafios e obstáculos. Campinas: Editora da Unicamp, 2007.

BUAINAIN, A. M.; BATALHA, M. O.

Cadeia Produtiva da Agroenergia. Série Agronegócios, Volume 3. Ministério da Agricultura, Pecuária e Abastecimento (MAPA) e Instituto Interamericano de Cooperação para a Agricultura (IICA), Brasil, 2007.

CARDOSO, Andreza Soares.

Sustentabilidade e gestão ambiental no município de Moju/PA: desafios para a produção do biodiesel. 2014. $86 \mathrm{f}$. Dissertação (Mestrado) - Universidade Federal do Pará, Museu Paraense Emílio Goeldi, Empresa Brasileira de Pesquisa Agropecuária, Belém, 2014. Programa de Pós-Graduação em Ciências Ambientais.

CASTRO, A. M. G.; LIMA, S. M. V.; SILVA, J. F. V. Complexo Agroindustrial do Biodiesel: Competitividade das Cadeias Produtivas de Matérias-Primas. Brasília, DF: Embrapa Agroenergia, 2010.

CÉSAR, A. S. Análise dos direcionadores de competitividade para a cadeia produtiva de biodiesel: o caso da mamona. 2009. 171 p. Dissertação (Mestrado) - Departamento de Engenharia e Produção, Universidade Federal de São Carlos, 2009.

COSTA, A. O. A Inserção do Biodiesel na Matriz Energética Nacional: Aspectos Socioeconômicos, Ambientais e Institucionais. Rio de Janeiro: UFRJ/ COPPE, XV, Tese de Doutorado, 2017. 
CUNHA, M. P. Avaliação socioeconômica e ambiental de rotas de produção de biodiesel no Brasil, baseada em análise de insumoproduto. Tese de Doutorado. Universidade Estadual de Campinas, Faculdade de Engenharia Mecânica, Campinas, SP: 2011. FARIA, A. C.; MARTINS, D. M.; SILVEIRA, M. A. P.; FARINA, M. C. O Valor Percebido para o Consumidor nas Dimensões Socioambiental, Econômica e Tecnológica da Cadeia Produtiva do Biodiesel. Revista Estudos do CEPE, Santa Cruz do Sul, n. 37, p. 78-101, 2013.

FIGUEIREDO, M. G. Agricultura e Estrutura Produtiva do Estado do Mato Grosso: Uma análise de insumo-produto. Dissertação de Mestrado. Universidade de São Paulo, Escola Superior de Agricultura Luiz de Queiroz, Piracicaba, SP: 2003.

FREITAS, S. M.; LUCON, O. Programa nacional de produção e uso de biodiesel: a transição para um estilo de desenvolvimento sustentável. Textos para discussão, São Paulo, n. 27, maio 2011. Disponível em: <ftp://ftp.sp.gov.br/ftpiea/ td/td-27-2011.pdf $>$. Acesso em: 19 jun. 2019. FROZZA, M. S.; TATSCH, A. L. Sistema setorial do biodiesel no Rio Grande do Sul: caracterização e oportunidades para a consolidação de um sistema inovativo em Agroenergia. Ciência Rural, Santa Maria, v. 44, n. 12, p. 2286-2292, 2014.

GARCIA, J. R. O Programa Nacional de Produção e Uso do Biodiesel brasileiro e a agricultura familiar na Região Nordeste. Dissertação de Mestrado. Universidade Estadual de Campinas, Instituto de Economia. Campinas, SP, 2007.

GIL, A. Métodos e técnicas de pesquisa social. 6. ed. São Paulo: Atlas, 2008.

GUIMARÃES, A. F. Distribuição geográfica e conjuntura atual das usinas de biocombustíveis da região Sul do Brasil. 2017. 132 f.. Dissertação (Mestrado em Bioenergia) - Universidade Estadual do Oeste do Paraná, Toledo, 2017.

HIRAKURI, M. H.; CONTE, O.; PRANDO, A. M.; CASTRO, C.; BALBINOT JUNIOR,
A. A. Diagnóstico da produção de soja na macrorregião sojícola. Londrina: Embrapa Soja, 2018.

ISOLANI, K. A.; TONIN, J. M. Produção de biodiesel no Brasil com o advento do Selo Combustível Social e os impactos na agricultura familiar. Revista Desenvolvimento e Meio Ambiente, Editora UFPR, Curitiba, v. 28, p. 157-171, jul./dez. 2013.

LEITE, J. G. D. B.; BIJMAN, J.; GILLER, K.; SLINGERLAND, M. Biodiesel policy for family farms in Brazil: One-size-fits-all? Environmental Science \& Policy, 27, 2013, p.195-205. Disponivel em: https://bit. ly/32kBGiE. Acesso em: 15 jun. 2020.

LIMA, A. E M. A Teoria do Desenvolvimento Regional e o papel do Estado. Revista de Análise Econômica. Porto Alegre, Faculdade de Ciências Econômicas: UFRGS, ano 24, n. 45, p. 65-90, 2006.

MAPA - Ministério da Agricultura, Pecuária e Abastecimento, 2019. Empresas com Selo Combustível Social - Atualizado em $1^{\circ}$ de agosto de 2019. Disponível em: https:// bit.ly/3aPAuYk. Acesso em: 28 ago. 2019. MARTINS, R.; NACHILUK, K.; BUENO, C. R. F.; FREITAS, S. M. O Biodiesel de Sebo Bovino no Brasil. Revista de Informações Econômicas, São Paulo, v. 41, n. 5, maio 2011. MDIC - Ministério do Desenvolvimento, Indústria e Comércio Exterior. Série Política Industrial, Tecnológica e de Comércio Exterior. O futuro da indústria: biodiesel. Coletânea de artigos. IN: FERREIRA, J. R.; CRISTO, C. M. P. N. Brasília: MDICSTI/IEL, 2006.

MONTEIRO, J. M. G. Plantio de Oleaginosas por Agricultores Familiares do Semiárido Nordestino para Produção de Biodiesel como uma Estratégia de Mitigação e Adaptação às Mudanças Climáticas. Rio de Janeiro: UFRJ/ COPPE, XV, Tese de Doutorado, 2007.

OLIVÉRIO, J. L.; BARREIRA, S. T.; RANGEL, S. C. P. Integrated Biodiesel Production In Barralcool Sugar And Alcohol Mill. Zuckerindustrie, v. 133, n. 2, p. 94-100, Feb 2008. 
PEDROTI, P. M. Os Desafios do

Desenvolvimento e da Inclusão Social: o caso do arranjo político-institucional do Programa Nacional de Produção e Uso de Biodiesel. Instituto de Pesquisa Econômica Aplicada (IPEA), Texto para Discussão, 1858, Rio de Janeiro: IPEA, 2013.

RAMOS, L. P.; KOTHE, V.; CÉSAROLIVEIRA, M. A. F.; MUNIZ-WYPYCH, A. S.; NAKAGAKI, S.; KRIEGER, N.; WYPYCH, F.; CORDEIRO, C. S. Biodiesel: matériasPrimas, Tecnologias de Produção e Propriedades Combustíveis. Revista Virtual Química. v. 9, ed. 1, p. 317-369, 2017.

RIBEIRO, E. C. B.; MOREIRA, A. C.; FERREIRA, L. M. D. F.; CÉSAR, A. S. Biodiesel and social inclusion: An analysis of institutional pressures between biodiesel plants and family farmers in southern Brazil. Journal of Cleaner Production, v. 204, p. 726-734, 2018.

RODRIGUES, R. Biodiesel no Brasil: diversificação energética e inclusão social com sustentabilidade. In: FERREIRA, J. R.; CRISTO, C. M. P. N. (Orgs.). O futuro da indústria: biodiesel - coletânea de artigos. Brasília, 2006. p. 15-25.

RODRIGUES, M. Agricultura familiar e produção de biodiesel: uma análise no Norte Mato-grossense. RACE, Revista de Administração, Contabilidade e Economia, Joaçaba: Ed. Unoesc, v. 14, n. 3، p. 889-904, set./dez. 2015. Disponível em: https://bit. ly/32iaroW. Acesso em: 24 mai. de 2019.

RODRIGUES, M.; ZAVALA, A. A. Z.

Programa Nacional de Biodiesel e Agricultura Familiar em Mato Grosso. REFAE, Revista da Faculdade de Administração e Economia, v. 8, n. 2, p. 172188, 2017.
SAMPAIO, R. M. Biodiesel no Brasil: Capacidades Estatais, P\&D e Inovação na Petrobras Biocombustíveis. Tese de Doutorado. Universidade Estadual de Campinas, Instituto de Geociências. Campinas, SP, 2017.

SILVA, M. S.; FERNANDES, F. M.; TEIXEIRA, F. L. C.; TORRES, E. A.; ROCHA, A. M. Biodiesel and the "Social Fuel Seal" in Brazil: Fuel of Social Inclusion? Journal of Agricultural Science, v. 6, n. 11, p. 212-228, 2014.

SILVA, M. S.; FERNANDES, F. M.; ROCHA, A. M.; LEAL, R. B. R. Cadeia de Produção Agroindustrial do Biodiesel na Bahia: Caracterização e Diagnóstico do Elo Agropecuário. Revista E.T.C. Educação, tecnologia e cultura. Bahia, n. 16, 2016, p. 1-20.

SOUZA, S. P.; SEABRA, J. E. A.;

NOGUEIRA, L. A. H. Feedstocks for biodiesel production: brazilian and global perspectives. Biofuels, v. 9, n. 4, 2017, p. 455-478.

TIBURCIO, B. A. Atores sociais, agricultura familiar e desenvolvimento territorial: uma análise do Programa Nacional de Produção e Uso de Biodiesel. 2011. 234 p. Tese (Doutorado em Desenvolvimento, Agricultura e Sociedade). Instituto de Ciências Humanas e Sociais, Universidade Federal Rural do Rio de Janeiro, Rio de Janeiro, RJ, 2011.

WESZ JUNIOR, V. J.; GRISA, C. O Estado e a soja no Brasil: a atuação do crédito rural de custeio (1999-2015). In: MALUF, R. S.; FLEXOR, G. (Orgs.). Questões agrárias, agrícolas e rurais: Conjunturas e políticas públicas. Rio de Janeiro, RJ: E-Papers, 2017.

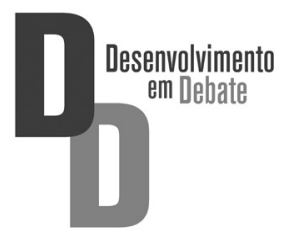

